\title{
Budgetary Impact on a U.S. Health Plan Adopting Abiraterone Acetate Plus Prednisone for the Treatment of Patients with Metastatic Castration-Resistant Prostate Cancer
}

\author{
Sonja Sorensen, MPH; Lorie Ellis, PhD; Ying Wu, PhD, MPH; Valerie Hutchins, BA; \\ John E. Linnehan, MPH; and Mekré Senbetta, PharmD
}

\begin{abstract}
BACKGROUND: Abiraterone acetate, an androgen biosynthesis inhibitor, received FDA approval in 2011 for metastatic castration-resistant prostate cancer (mCRPC) patients who have received prior chemotherapy containing docetaxel.
\end{abstract}

OBJECTIVE: To estimate the projected budgetary impact of adopting abiraterone for mCRPC patients from a U.S. health plan perspective.

METHODS: A decision analytic model compared mCRPC treatment cost before and after abiraterone acetate adoption based on a hypothetical 1,000,000-member plan. Plan mCRPC prevalence was derived from prostate cancer incidence reported in U.S. epidemiology statistics and disease progression data from published trials. Market shares for comparator mCRPC treatments (prednisone alone; cabazitaxel + prednisone; mitoxantrone + prednisone; docetaxel retreatment + prednisone) were derived from market research simulation. Abiraterone + prednisone uptake (8\% scenario 1 to $55 \%$ - scenario 3) was based on assumptions for illustrative purposes. Treatment costs were computed using prescribing information, treatment duration from phase III trials, and drug costs considering common U.S. cost listing and reimbursement schemes. Prevalence and costs of managing treatment-related toxicities were estimated from literature, treatment guidelines, and expert clinical opinion. The model evaluated the perspectives of a commercial payer with no Medicare beneficiaries and a commercial payer with a subset of Medicare beneficiaries. Sensitivity analyses were conducted to assess changing input values.

RESULTS: In each modeled scenario, 57 patients with prior docetaxel therapy received treatment for $\mathrm{mCRPC}$. For the commercial perspective, the incremental per-member-per-month (PMPM) cost attributable to abiraterone ranged from $\$ 0.0019$ in scenario 1 to $\$ 0.0133$ in scenario 3 . For the commercial/Medicare perspective, the incremental PMPM ranged from $\$ 0.0026$ in scenario 1 to $\$ 0.0176$ in scenario 3 . The average incremental PMPM cost over 3 scenarios is $\$ 0.0112$. When testing key sensitivity scenarios, the model indicated that abiraterone treatment duration and cabazitaxel market share were the main drivers of cost.

CONCLUSIONS: The model results indicate that reimbursement for abiraterone may have a neutral impact on a U.S. health plan budget given the relatively small size of the eligible prostate cancer population and expected lower toxicity-related costs as compared with chemotherapy. The sensitivity analyses addressing the components of uncertainty in the model show that the budgetary impact of abiraterone is likely low.

J Manag Care Pharm. 2013;19(9):799-808

Copyright $\odot 2013$, Academy of Managed Care Pharmacy. All rights reserved.

\section{What is already known about this subject}

- Metastatic castration-resistant prostate cancer (mCRPC), defined as disease progression associated with rising serum prostate-specific antigen levels despite surgical or medical castration, is relatively rare. Only a small fraction of all prostate cancer patients progress to $\mathrm{mCRPC}$ and, these patients have a poor survival prognosis.

- Docetaxel is the primary agent used in first-line treatment of symptomatic mCRPC and, until recently, has been the only agent to show a survival benefit, prolonging life for 2 to 3 months.

- In 2011, two new treatments, abiraterone acetate and cabazitaxel, were approved by the FDA and have shown a survival benefit in MCRPC patients who have received prior chemotherapy containing docetaxel.

\section{What this study adds}

- This study is the first to estimate the potential annual budgetary impact of introducing abiraterone acetate to the current treatment options, including cabazitaxel, for mCRPC patients who have received prior chemotherapy containing docetaxel.

- The model results indicate that reimbursement for abiraterone may have a neutral impact on a U.S. health plan budget given the relatively small size of the eligible prostate cancer population and expected lower toxicity-related costs as compared with chemotherapy. The sensitivity analyses addressing the components of uncertainty in the model show that the budget impact of abiraterone is likely low.

- This analysis does not consider enzalutamide, which was approved by the FDA for treatment of mCRPC post-docetaxel after this current study was conducted. The listed average wholesale price (AWP) of a 30-day supply of enzalutamide is $\$ 7,778$ (AWP less $13 \%$ ), and the median duration of treatment seen in the pivotal clinical trial was 8.3 months, compared with abiraterone 30 -day costs of less than $\$ 6,000$ (AWP less 13\%) and a similar median treatment duration. The drug costs are the major driver of the permember-per-month calculation. 


\section{Budgetary Impact on a U.S. Health Plan Adopting Abiraterone Acetate Plus Prednisone for the Treatment of Patients with Metastatic Castration-Resistant Prostate Cancer}

$\mathrm{P}$ rostate cancer is the most common nonskin cancer found in American men. In 2010, approximately 32,000 deaths were attributed to prostate cancer. ${ }^{1}$ In the United States, prostate cancer-related expenditures from the year 2006 (\$9.9 billion), inflated to 2012 U.S. dollars, approached \$11.9 billion, making prostate cancer the fifth most costly cancer. In the same reference year, higher expenditures were attributed only to female breast cancer, colorectal cancer, lung cancer, and lymphoma. ${ }^{2}$

Although prostate cancer is prevalent, only a small percentage of all prostate cancer patients progress to metastatic castration-resistant prostate cancer (mCRPC) and even fewer advance to treatment with first- or second-line chemotherapy regimens. ${ }^{3}$ More than $90 \%$ of advanced prostate cancer patients have bone metastases, and 57\% have metastasis to soft tissue. ${ }^{4}$ Nearly all metastatic prostate cancer ultimately becomes castration resistant-usually within 13-21 months from initiation of hormonal therapy among untreated patient $s^{5-7}$-at which point very few treatments have demonstrated an impact on patient survival.

$\mathrm{mCRPC}$ is defined by the occurrence of disease progression typically with associated rising serum prostate-specific antigen (PSA) levels despite surgical or medical castration. In mCRPC patients who are candidates for chemotherapy, docetaxel is the only first-line chemotherapeutic option for symptomatic mCRPC that provides an overall survival benefit with dosing every 3 weeks (median survival $=19$ months). ${ }^{8}$ After docetaxel failure, 2 recently approved second-line therapies provide an overall survival benefit-cabazitaxel (2.4-month survival benefit over mitoxantrone+ prednisone $)^{9,10}$ and abiraterone acetate (3.9- to 4.6-month survival benefit over placebo + prednisone). ${ }^{11-13}$ Cabazitaxel is a cytotoxic chemotherapeutic agent that has been associated with significant myelosuppressive adverse events, ${ }^{9}$ while abiraterone acetate is a novel oral androgen biosynthesis inhibitor that inhibits CYP17A and blocks steroid biosynthesis in the adrenal gland, the testes, and within the prostate tumor. Abiraterone acetate has been shown to be well tolerated and without the toxicity of chemotherapy. ${ }^{12}$

Given the significant annual cost of treating prostate cancer in the United States, health plan budget holders must be cognizant of the financial impact of new treatments. The use of a budget impact model (BIM) is helpful in this regard, as BIMs improve the understanding of how the introduction of one such treatment, in this case abiraterone acetate, impacts the health plan budget from a U.S. third-party payer perspective. National regulatory agencies throughout the world and managed care organizations in the United States recognize the importance of budget impact analysis in a comprehensive economic assessment of new health care interventions and several require that companies submit BIMs in addition to cost-effectiveness estimates. ${ }^{14}$ This study presents an analysis of the budgetary impact of including abiraterone acetate as a treatment for MCRPC patients who have failed docetaxel.

\section{Methods}

This BIM was developed in accordance with the 2010 Academy of Managed Care Pharmacy (AMCP) evidence requirements for formulary submission ${ }^{15}$ and consideration for the principles of good practice for budgetary impact analysis from the International Society for Pharmacoeconomics and Outcomes Research (ISPOR) Task Force on Good Research Practices. ${ }^{14}$ The model estimates the incremental budgetary impact of adopting abiraterone in combination with prednisone as a treatment option for patients who have been diagnosed with mCRPC and have received chemotherapy containing docetaxel. The model combines epidemiological data, market research simulation assumptions, expert opinion, and drug and toxicity costs. Treatments approved for post-docetaxelcontaining chemotherapy are considered in the model. These treatment options include cabazitaxel + prednisone, mitoxantrone + prednisone, docetaxel (retreatment) + prednisone, and prednisone monotherapy. The model does not include treatment-monitoring costs.

\section{Perspective and Time Horizon}

The budget impact of abiraterone uptake is estimated from 2 perspectives: (1) a commercial payer with no Medicare beneficiaries, and (2) a commercial payer with a subset of Medicare beneficiaries. The BIM considers costs on an annual basis for 3 different market share scenario assumptions that account for increased uptake of abiraterone over time. An average budget impact of the 3 scenarios is also considered. The percentage of prostate cancer patients who are Medicare beneficiaries is 57\%, estimated from an analysis of a large employer database. ${ }^{16}$

\section{Population Estimates}

The BIM considers a hypothetical health plan size of $1,000,000$ members. It is assumed that $49.2 \%{ }^{17}$ of members are male, consistent with the proportion of adult men in the general U.S. population in 2009. While the total health plan size is assumed, this assumption does not affect the summary outcomes of the model cost per member per month (PMPM).

The model calculates the number of MCRPC patients who have received chemotherapy containing docetaxel and who are treated with a second-line agent through a step-wise process based on a dynamic progression model. ${ }^{3}$ First, the total number of patients with prostate cancer at any stage was calculated by multiplying the age-adjusted rate $(0.14 \%)^{3,18}$ of newly diagnosed prostate cancer by the male plan population of 492,000. Second, the percentage of all prostate cancer cases that progress to $\mathrm{MCRPC}$ and that have received prior chemotherapy containing docetaxel $(9 \%)^{3,8,19-22}$ was applied to the health plan's prostate cancer population to estimate the final eligible post-docetaxel chemotherapy mCRPC population. The final population of eligible patients per year was estimated to be 57 in a 1,000,000-member health plan. The model assumes that the size and epidemiological makeup of the eligible model population remains constant for the 3 different scenarios and 
Budgetary Impact on a U.S. Health Plan Adopting Abiraterone Acetate Plus Prednisone for the Treatment of Patients with Metastatic Castration-Resistant Prostate Cancer

TABLE 1 Market Share BIM Assumptions

\begin{tabular}{|c|c|c|c|c|}
\hline & \multirow{2}{*}{$\begin{array}{l}\text { Pre-Abiraterone } \\
\text { Scenario } \\
(\%)\end{array}$} & \multicolumn{3}{|c|}{ With Abiraterone } \\
\hline & & $\begin{array}{c}\text { Scenario l } 1 \\
(\%)\end{array}$ & $\begin{array}{c}\text { Scenario } 2 \\
(\%)\end{array}$ & $\begin{array}{c}\text { Scenario } 3 \\
(\%)\end{array}$ \\
\hline Abiraterone + prednisone ${ }^{a}$ & - & 8 & 42 & 55 \\
\hline Prednisone monotherapy & 15 & 14 & 9 & 7 \\
\hline Cabazitaxel + prednisone & 66 & 61 & 38 & 30 \\
\hline Mitoxantrone + prednisone & 15 & 14 & 9 & 7 \\
\hline Docetaxel retreatment + prednisone & 4 & 4 & 2 & 2 \\
\hline Total & 100 & 100 & 100 & 100 \\
\hline
\end{tabular}

Source: Assumption-based simulations.

${ }^{a}$ Abiraterone market share does not reflect comparison with the listed prostate cancer treatments.

BIM = budget impact model.

for the 2 payer populations. Given that a commercial payer with a subset of Medicare beneficiaries could have a somewhat older patient population and the number of $\mathrm{mCRPC}$ cancers is higher for older age groups, ${ }^{23}$ the model may underestimate the number of mCRPC cases in plans with Medicare beneficiaries and overestimate the number of cases in a commercial-only plan. Sensitivity analyses were conducted on these estimates.

\section{Model Inputs and Assumptions}

Market Share. Market shares for the comparator treatments considered in the model were estimated based on simulation of market research data including treatment analogs (Table 1). The market share estimates were computed prior to abiraterone launch, and these inputs were used for illustrative purposes only. Abiraterone market share was assumed to increase over each of the 3 annual market share scenarios, with the share of all other comparator drugs decreasing in proportion to their respective share in the pre-abiraterone scenario. The market share scenarios presented are not intended to represent comparisons between alternative prostate cancer treatments. Additionally, combination use of the listed agents is not considered, with the exception of prednisone.

Clinical Inputs. The model allows for consideration of clinical inputs such as treatment duration, dosing regimens, and frequency of toxicities.

Patients with mCRPC typically discontinue treatment due to disease progression, occurrence of severe toxicity, or because a given drug has a maximum recommended cumulative dose or number of treatment cycles. Consequently, for the purpose of the model, drug costs were applied over a specified treatment duration. The modeled treatment duration is defined as the median treatment duration reported in clinical trials for each treatment. Because prednisone has palliative effects, its use is recommended indefinitely, even after discontinuation of other prostate cancer therapies considered in this model. Due to the annual calculation metric, the model uses a 12-month treatment duration for prednisone. For simplicity, dose reductions were not considered.
Dosing regimens for the various drugs were based upon prescribing information for each drug included in the model. In the case of chemotherapeutic agents, standard dosing regimens and frequencies from the literature were used and converted to cycles of 3 weeks where appropriate. Drug doses based on body surface area were calculated for a male with a 2.02-squaremeter $\left(\mathrm{m}^{2}\right)$ surface area. ${ }^{24}$ The model inputs for abiraterone dosing were 1,000 milligrams (mg) administered orally once daily for 8 months. ${ }^{11}$ For cabazitaxel, the model assumptions specify $25 \mathrm{mg} / \mathrm{m}^{2}$ administered via intravenous (IV) infusion every 3 weeks for 6 cycles (in total, 4.1 months). ${ }^{9}$ For mitoxantrone, $12 \mathrm{mg} / \mathrm{m}^{2}$ are administered via IV infusion every 3 weeks for 4 cycles (in total, 2.8 months). ${ }^{9}$ Retreatment with docetaxel is given at a dose of $75 \mathrm{mg} / \mathrm{m}^{2}$ via IV infusion every 3 weeks for 9.5 cycles (in total, 6.6 months). ${ }^{8}$ It is assumed that median treatment duration of docetaxel retreatment is identical to that of first-line docetaxel. Prednisone is dosed at $5 \mathrm{mg}$ orally ${ }^{11}$ twice daily for 12 months.

Each treatment considered in the model has a unique safety profile with cost implications to payers (Table 2). Therefore, the cost of treating toxicities was considered in this model. Toxicities for those events that had the greatest difference in frequency between treatments were evaluated. This method of comparison reflects the incremental financial impact to payers when a new therapy is adopted. Only grade 3 and grade 4 toxicities were considered, as these have the greatest impact on cost. Sources of toxicity frequency include clinical trial publications and manufacturer prescribing information.

Drug Costs. The drug costs were calculated using costing methods reported in AMCP's Guide to Pharmaceutical Payment Methods (Table 3) with the intent to mimic current payer practices for reimbursement. ${ }^{25}$ Costs of oral drugs were calculated as average wholesale price (AWP) less 13\%. Costs of IV drugs were calculated as average sales price (ASP) plus $10 \%$ from the commercial perspective and plus $6 \%$ from the Medicare perspective. Drug wastage, defined as disposal rather than reuse of a vial that is partially used, was considered for cabazitaxel and docetaxel because the labels specify single use 
TABLE 2 Frequency and Costs of Key Grade 3 and Grade 4 Toxicities

\begin{tabular}{|c|c|c|c|c|c|c|c|}
\hline \multirow[b]{2}{*}{ Anemia } & \multirow{2}{*}{\begin{tabular}{|c|}
$\begin{array}{c}\text { Total Cost of } \\
\text { Treating an Episode } \\
\text { of Grade } 3 \text { and } \\
\text { Grade 4 Toxicity (\$) }\end{array}$ \\
4,082 \\
\end{tabular}} & $\begin{array}{c}\text { Abiraterone + } \\
\text { Prednisone } e^{\mathrm{a}, \mathrm{b}} \\
\quad(\$, \%)\end{array}$ & $\begin{array}{c}\text { Prednisone } \\
\text { Monotherapy } \\
(\$, \%)\end{array}$ & $\begin{array}{c}\text { Cabazitaxel + } \\
\text { Prednisone } \\
(\$, \%)\end{array}$ & $\begin{array}{c}\text { Mitoxantrone + } \\
\text { Prednisone } e^{\mathrm{c}} \\
(\$, \%)\end{array}$ & \multicolumn{2}{|c|}{$\begin{array}{c}\text { Docetaxel } \\
\text { Retreatment } \\
\text { Prednisone } \mathrm{d}, \mathrm{c} \\
(\$, \%)\end{array}$} \\
\hline & & $306 \quad(7.5)$ & $302 \quad(7.4)$ & $449 \quad(11)$ & $204 \quad(5)$ & 204 & $(5)$ \\
\hline Arthralgia & \begin{tabular}{|c|}
15 \\
\end{tabular} & $1 \quad(4.2)$ & $(4.1)$ & (1) & (1) & 0 & (1) \\
\hline Diarrhea & 278 & $2 \quad(0.6)$ & $4 \quad(1.3)$ & (6) & $(0.3)$ & 6 & $(2)$ \\
\hline Fatigue/asthenia & 22 & $2(10.6)$ & $3(11.9)$ & $(10)$ & (5) & 1 & $(5)$ \\
\hline Hypokalemia & 1,432 & $76 \quad(5.3)$ & $14 \quad(1.0)$ & $(0)$ & $(0)$ & 0 & $(0)$ \\
\hline Neutropenia (nonfebrile) & 2,946 & $3 \quad(0.1)$ & $(0.3)$ & 2,416 & 1,709 & 943 & $(32)$ \\
\hline Neutropenia (febrile) & 14,129 & $0 \quad(0)$ & $(0)$ & 1,130 & 141 & 424 & (3) \\
\hline Thrombocytopenia & 1,021 & $14 \quad(1.4)$ & $5 \quad(0.5)$ & $41 \quad(4)$ & $20 \quad(2)$ & 10 & (1) \\
\hline Total cost of toxicities & & 404 & 337 & 4,055 & 2,077 & 1,5 & \\
\hline $\begin{array}{l}\text { aZytiga drug label.12 } \\
\text { bde Bono JS, et al., Abirater } \\
\text { 'de Bono JS, et al., Prednisor } \\
\text { open-label trial.9 } \\
\text { dTannock IF, et al., Docetax } \\
\text { 'Taxotere drug label.27 }\end{array}$ & $\begin{array}{l}\text { and increased survival in } \\
\text { lus cabazitaxel or mitox } \\
\text { lus prednisone or mitoxa }\end{array}$ & $\begin{array}{l}\text { metastatic prostat } \\
\text { ntrone for metasta } \\
\text { trone plus prednis }\end{array}$ & $\begin{array}{l}\text { cer. }^{11} \\
\text { astration-resistant } \\
\text { or advanced prosta }\end{array}$ & $\begin{array}{l}\text { ate cancer progres } \\
\text { ncer. }{ }^{8}\end{array}$ & after docetaxel trea & nt: a rand & mized \\
\hline
\end{tabular}

only. Wastage was not considered for mitoxantrone because the label specifies it can be reused if stored properly. ${ }^{26} \mathrm{~A}$ vial size of $60 \mathrm{mg}$ was considered for cabazitaxel, a size of $20 \mathrm{mg}$ for mitoxantrone, and a size of $160 \mathrm{mg}$ for docetaxel. ${ }^{10,26,27}$

Toxicity Costs. There is very little published literature that explores the costs of toxicities in the context of metastatic prostate cancer. Therefore, multiple methods were used to derive cost estimates (Table 2).

The costs of treating grade 3 and grade 4 neutropenia (febrile and nonfebrile) were based on a published SEERMedicare database analysis in non-small cell lung cancer patients. ${ }^{28}$ For all other grade 3 and grade 4 toxicities, management costs were determined by weighting the cost of inpatient and outpatient management. The inpatient costs were determined by claims data analysis of the Health Care Utilization Project (HCUP) Nationwide Inpatient Sample, which reports data from a national sample of more than 1,000 hospitals. ${ }^{29}$ HCUP costs were inflated from 2009 to 2012 equivalents using the Consumer Price Index for medical care. ${ }^{30}$ Outpatient costs were derived from a variety of sources. Costs related to outpatient management of anemia were based on a prospective, observational study of clinical practice of patients receiving erythropoiesis-stimulating agents and blood transfusions for chemotherapy-induced anemia. ${ }^{31}$ Outpatient costs for the remaining toxicities were based on the common procedures and medications used to identify and treat the toxicity. Such procedures and medications were based on National Comprehensive Cancer Network (NCCN) treatment guidelines $^{32,33}$ and were supplemented with expert input when needed. Similarly, expert input defined the mix of patients treated in the inpatient or outpatient setting. The cost estimates for outpatient treatment of toxicities relied upon assumptions for medication costs using wholesale acquisition cost (WAC) from RedBook and procedure costs from Physicians' Fee E Coding Guide and CMS Physician Fee Schedule - National Payment Amount File CY 2012. ${ }^{34-36}$

Total costs of treating toxicities for each treatment regimen are shown in Table 2. A key assumption regarding toxicities is that treatment and cost are assumed to be the same regardless of the drug that caused the toxicity. Similarly, costs of treating toxicities are assumed not to change based on the perspective selected.

Model Analyses. The model calculates the health plan budget spent on treatments for mCRPC and includes costs for both active treatment (including administration) and costs for grade 3 and grade 4 toxicity management. Both incremental and absolute health plan costs are calculated from both perspectives. The results of the BIM output focus on cost PMPM and cost per member per year, which allow generalization to a variety of enduser scenarios with different inputs and assumptions.

\section{Results}

For the commercial and commercial/Medicare scenarios outlined above, abiraterone has minimal budget impact. When added to health plan formularies, abiraterone takes market share primarily from cabazitaxel. The addition of abiraterone to health plans with commercial or commercial/Medicare perspectives increased the cost of active treatment but offset or reduced most of the increase by comparatively reducing costsassociated with treatment of toxicities. The cost offsets were primarily attributed to abiraterone's manageable safety profile. For the commercial perspective, the incremental PMPM cost ranged from $\$ 0.0019$ in scenario 1 to $\$ 0.0133$ in scenario 3. The average incremental cost PMPM over the 3 scenarios is $\$ 0.0085$. 
Budgetary Impact on a U.S. Health Plan Adopting Abiraterone Acetate Plus Prednisone for the Treatment of Patients with Metastatic Castration-Resistant Prostate Cancer

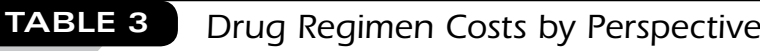

\begin{tabular}{|c|c|c|c|}
\hline Comparator & Cost Per Month (\$) & Administration Cost Per Month ${ }^{\mathrm{a}, \mathrm{b}}(\$)$ & Total Cost Per Monthc (\$) \\
\hline \multicolumn{4}{|l|}{ Commercial perspective } \\
\hline Abiraterone + prednisone & $5,817^{\mathrm{d}}$ & 0 & 5,817 \\
\hline Prednisone monotherapy & $1^{\mathrm{d}}$ & 0 & 1 \\
\hline Cabazitaxel + prednisone & $12,890^{e, f, g}$ & 659 & 13,549 \\
\hline Mitoxantrone + prednisone & $306^{\mathrm{e}, \mathrm{g}}$ & 659 & 964 \\
\hline Docetaxel + prednisone & $3,549 \mathrm{e}, \mathrm{f}, \mathrm{g}$ & 659 & 4,208 \\
\hline \multicolumn{4}{|l|}{ Medicare perspective } \\
\hline Abiraterone + prednisone & $5,817^{\mathrm{d}}$ & 0 & 5,817 \\
\hline Prednisone monotherapy & $1^{\mathrm{d}}$ & 0 & 1 \\
\hline Cabazitaxel + prednisone & $12,421^{\mathrm{f}, \mathrm{g}, \mathrm{h}}$ & 199 & 12,621 \\
\hline Mitoxantrone + prednisone & $294^{f, h}$ & 199 & 494 \\
\hline Docetaxel + prednisone & $3,420^{f, g, h}$ & 199 & 3,619 \\
\hline
\end{tabular}

aPhysicians Fee \& Coding Guide, 2012.36

${ }^{b}$ Three weekly administration costs were adjusted to 1 month (1.4 doses per month at a cost of $\$ 456$ or $\$ 138$ per administration for the commercial and Medicare perspectives, respectively).

cDue to rounding some of total costs are not exactly a sum of the cost per month and administration cost.

${ }^{d}$ Costs based on average wholesale price (AWP) $-13 \% .35$

${ }^{e}$ Costs based on average sale price (ASP) $+10 \% .{ }^{37}$

${ }^{f}$ Costs based on ASP + 6\%. ${ }^{37}$

¿Drug wastage is considered in the cost.

hBody surface area (BSA) of $2.02 \mathrm{~m}^{2}$ is used to calculate the drug cost. ${ }^{24}$

Incremental costs are shown in Table 4. For the commercial/ Medicare perspective, the incremental PMPM ranged from $\$ 0.0026$ in scenario 1 to $\$ 0.0176$ in scenario 3. The average incremental PMPM cost over the 3 scenarios is $\$ 0.0112$. Overall costs to the hypothetical health plan are shown in Table 5 .

\section{Sensitivity Analyses}

The model is sensitive to several parameters, including abiraterone treatment duration and cabazitaxel market share assumption. One-way sensitivity analyses highlight the parameters to which the model is most sensitive. The average incremental cost PMPM over the 3 scenarios is used to explore the results (Figure 1 and Figure 2).

Because abiraterone can be given until disease progression, the median treatment duration may not represent the full extent of abiraterone use. In sensitivity analysis of abiraterone treatment duration, the treatment duration was changed from 8 months to 12 months. This change had the biggest impact on model results. From the commercial perspective, the average incremental PMPM cost increased from $\$ 0.0085$ for an 8 -month treatment duration to $\$ 0.0472$ for a 12 -month treatment duration. From the commercial/Medicare perspective, the average incremental PMPM cost increased from $\$ 0.0112$ for an 8-month treatment duration to $\$ 0.0499$ for a 12 -month treatment duration.

Cabazitaxel has a majority of the market share in the base case. To test the sensitivity of this value, the model decreases the market share of cabazitaxel from $66 \%$ to $50 \%$ and $40 \%$ separately. The market share taken from cabazitaxel is split evenly between prednisone monotherapy and mitoxantrone + prednisone. From the commercial perspective, the decrease of cabazitaxel market share to $50 \%$ and $40 \%$ increases the average incremental cost PMPM from $\$ 0.0085$ to $\$ 0.0240$ and $\$ 0.0336$, respectively. From the commercial/Medicare perspective, the decrease of cabazitaxel market share to $50 \%$ and $40 \%$ increases the average incremental cost PMPM from $\$ 0.0112$ to $\$ 0.0263$ and $\$ 0.0356$, respectively.

Other variables had little impact on the model results. Toxicity costs were lower for abiraterone than for most of the comparators treatments; therefore, when the costs of managing toxicities are excluded from the model, the average PMPM cost increases for abiraterone acetate. When drug costs are the only model input, the average incremental PMPM cost increases by a small amount for both perspectives (approximately \$0.005). Varying the proportion of eligible patients by $25 \%$ fewer or $25 \%$ greater than the base case resulted in the PMPM ranging from $\$ 0.0068$ to $\$ 0.0106$ from the commercial perspective. From a commercial/Medicare perspective, the PMPM was $\$ 0.0090$ to $\$ 0.0140$ when the proportion of mCRPC cases was varied by $25 \%$. Variations in body surface area (BSA) were also explored. The BSA reported in the abiraterone trial was 2.02 $\mathrm{m}^{2}$. A reduction in mean BSA of $0.215 \mathrm{~m}^{2}$, which is equivalent to 1 standard deviation in BSA in the abiraterone phase III clinical trial, had no effect on the budgetary impact from both perspectives, increasing the average PMPM cost by approximately $\$ 0.00002$ from both perspectives. Finally, when increasing the uptake of abiraterone to $33 \%$ in scenario 1, 45\% in scenario 2 , and $60 \%$ in scenario 3 , the average incremental PMPM cost increased $\$ 0.003$ and $\$ 0.004$ from the commercial and commercial/Medicare perspectives, respectively. 
Budgetary Impact on a U.S. Health Plan Adopting Abiraterone Acetate Plus Prednisone for the Treatment of Patients with Metastatic Castration-Resistant Prostate Cancer

\section{TABLE 4 Incremental Costs of Adding Abiraterone}

\begin{tabular}{|c|c|c|c|c|}
\hline & \multicolumn{3}{|c|}{ Incremental Cost Impact of Abiraterone ${ }^{\mathrm{a}}(\$)$} & $\begin{array}{c}\text { Average Incremental } \\
\text { Impact (\$) }\end{array}$ \\
\hline \multicolumn{5}{|l|}{ Commercial Perspective } \\
\hline Summary costs & Scenario 1 & Scenario 2 & Scenario 3 & \\
\hline Cost per member per month (PMPM) & 0.0019 & 0.0101 & 0.0133 & 0.0085 \\
\hline Cost per member per year (PMPY) & 0.0232 & 0.1218 & 0.1595 & 0.1015 \\
\hline Total costs & Scenario 1 & Scenario 2 & Scenario 3 & \\
\hline Active medication costs (all selected treatments) & 35,538 & 186,572 & 244,321 & 155,477 \\
\hline Cost of managing toxicities & $-12,340$ & $-64,786$ & $-84,838$ & $-53,988$ \\
\hline TOTAL & 23,197 & 121,787 & 159,482 & 101,489 \\
\hline \multicolumn{5}{|l|}{ Commercial/Medicare Perspective } \\
\hline Summary costs & Scenario 1 & Scenario 2 & Scenario 3 & \\
\hline Cost PMPM & 0.0026 & 0.0135 & 0.0176 & 0.0112 \\
\hline Cost PMPY & 0.0307 & 0.1614 & 0.2114 & 0.1345 \\
\hline Total costs & Scenario 1 & Scenario 2 & Scenario 3 & \\
\hline Active medication costs (all selected treatments) & 43,123 & 226,396 & 296,471 & 188,663 \\
\hline Cost of managing toxicities & $-12,379$ & $-64,988$ & $-85,103$ & $-54,157$ \\
\hline TOTAL & 30,744 & 161,408 & 211,368 & 134,507 \\
\hline
\end{tabular}

\section{TABLE 5 Overall Cost to Plan of Adding Abiraterone}

\begin{tabular}{|c|c|c|c|c|}
\hline & Pre-Abiraterone (\$) & \multicolumn{3}{|c|}{ Post-Abiraterone (\$) } \\
\hline \multicolumn{5}{|l|}{ Commercial Perspective $^{a}$} \\
\hline Summary costs & & Scenario 1 & Scenario 2 & Scenario 3 \\
\hline Cost per member per month (PMPM) & 0.1989 & 0.2008 & 0.2091 & 0.2122 \\
\hline Cost per member per year (PMPY) & 2.3869 & 2.4101 & 2.5087 & 2.5464 \\
\hline Total costs & & Scenario 1 & Scenario 2 & Scenario 3 \\
\hline Active medication costs (all selected treatments) & $2,209,639$ & $2,245,176$ & $2,396,211$ & $2,453,959$ \\
\hline Cost of managing toxicities & 177,282 & 164,942 & 112,496 & 92,443 \\
\hline TOTAL & $2,386,920$ & $2,410,118$ & $2,508,707$ & $2,546,403$ \\
\hline \multicolumn{5}{|l|}{ Commercial/Medicare Perspective $^{b}$} \\
\hline Summary costs & & Scenario 1 & Scenario 2 & Scenario 3 \\
\hline Cost PMPM & 0.1910 & 0.1936 & 0.2045 & 0.2086 \\
\hline Cost PMPY & 2.2921 & 2.3228 & 2.4535 & 2.5035 \\
\hline Total costs & & Scenario 1 & Scenario 2 & Scenario 3 \\
\hline Active medication costs (all selected treatments) & $2,114,820$ & $2,157,943$ & $2,341,216$ & $2,411,291$ \\
\hline Cost of managing toxicities & 177,268 & 164,889 & 112,280 & 92,165 \\
\hline TOTAL & $2,292,088$ & $2,322,833$ & $2,453,496$ & $2,503,456$ \\
\hline
\end{tabular}

\section{Discussion}

Abiraterone provides significant survival benefits as compared to prednisone for MCRPC patients who have previously received docetaxel. ${ }^{11}$ This study aimed to assist U.S. thirdparty payers in understanding the potential annual financial impact of introducing abiraterone acetate to health plan formularies through the use of a BIM. Due to the relatively small number of patients and the manageable safety profile of abiraterone, the model results suggest that abiraterone will have a minimal budget impact on health plans, increasing incremental PMPM costs an average of $\$ 0.0085$ and $\$ 0.0112$ over 3 annual market share scenarios from a commercial and commercial/Medicare perspective, respectively. The addition of abiraterone increases the costs of active drug treatment, in part because alternatives to abiraterone include relatively inexpensive generic products such as prednisone and mitoxantrone. However, these increased costs are partially offset as a result of the lower incidence of costly toxicities compared with other $\mathrm{mCRPC}$ treatments. The model is most sensitive to abiraterone 


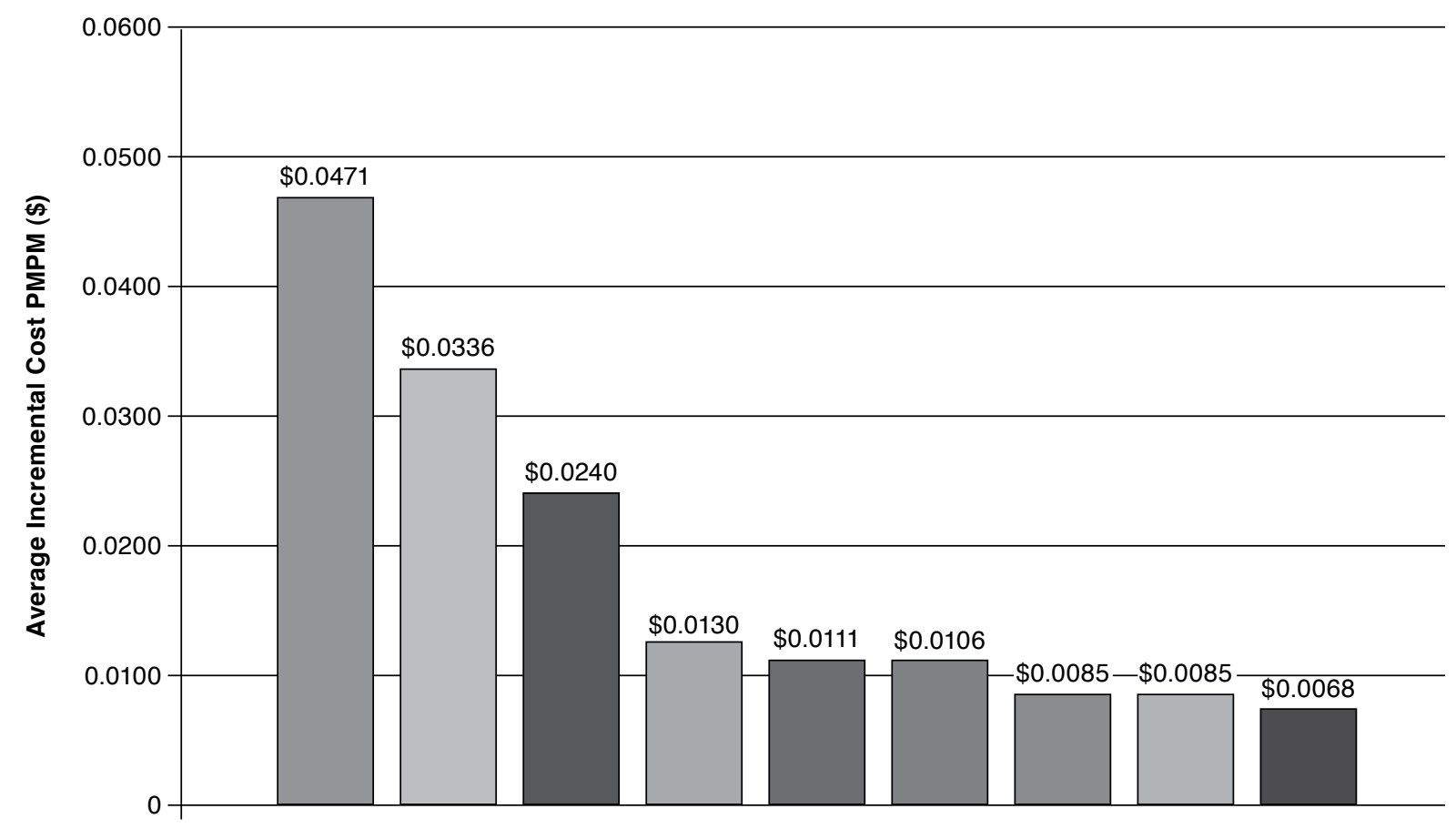

\begin{tabular}{|ll|}
\hline$\square$ AA treatment duration - 12 months & $\square$ Increased mCRPC cases - 25\% \\
$\square$ MS: Cabazitaxel - 40\% & $\square$ Body surface area of $1.8 \mathrm{~m}^{2}$ \\
$\square$ MS: Cabazitaxel - 50\% & $\square$ Base case \\
$\square$ Drug costs only & $\square$ Decreased mCRPC cases - 25\% \\
$\square$ Increased uptake of abiraterone & \\
(Scenario 2: 45\%; Scenario 3: 60\%) & \\
\hline
\end{tabular}

$A A=$ abiraterone acetate; $M S=$ market share; $m^{2}=$ square meter; $P M P M=$ per member per month; $m C R P C=$ metastatic castration-resistant prostate cancer .

treatment duration and the cabazitaxel market share assumptions. The impact of the latter assumptions is demonstrated by the observation that the more shares taken from cabazitaxel by abiraterone, the more cost offsets are realized by the plan.

There are no existing publications concerning budget impact results for mCRPC, making it difficult to interpret the model results in light of existing evidence. Budget impact results observed for therapies in second-line breast cancer and second- and third-line lung cancer provide the best proxies. For example, the addition of capecitabine to ixabepilone as a treatment option for treatment-refractory metastatic breast cancer resulted in an aggregated incremental cost PMPM of $\$ 0.005$ in year 1 and $\$ 0.006$ in years 2 and $3 .{ }^{38}$ The minimal budget impact is driven primarily by the fact that the population eligible for ixabepilone treatment was very small (15 among a 1,000,000-person plan). While these results are similar to the findings of the abiraterone BIM, the capecitabine/ixabepilone uptake was very small compared with the uptake assumption of abiraterone. Furthermore, adding erlotinib as a treatment option for second- and third-line treatment of advanced non-small cell lung cancer, where erlotinib was assumed to account for $30 \%$ of second-line treatment and $90 \%$ of thirdline treatment, resulted in an incremental cost PMPM of less than $\$ 0.010 .{ }^{39}$ Similar to our analysis, the small incremental cost PMPM was driven by lower administration costs and lower costs of treating adverse events in the group of patients receiving erlotinib. The uptake of erlotinib was more similar to the base case uptake we assumed for abiraterone- $8 \%$ in scenario 1 to $55 \%$ in scenario 3-and abiraterone resulted in a lower PMPM cost. Both of these publications asserted that the PMPM results indicated a low budget impact, suggesting that the abiraterone budget impact would also be low. 


\section{FIGURE 2 Sensitivity Analyses - Commercial/Medicare Perspective}
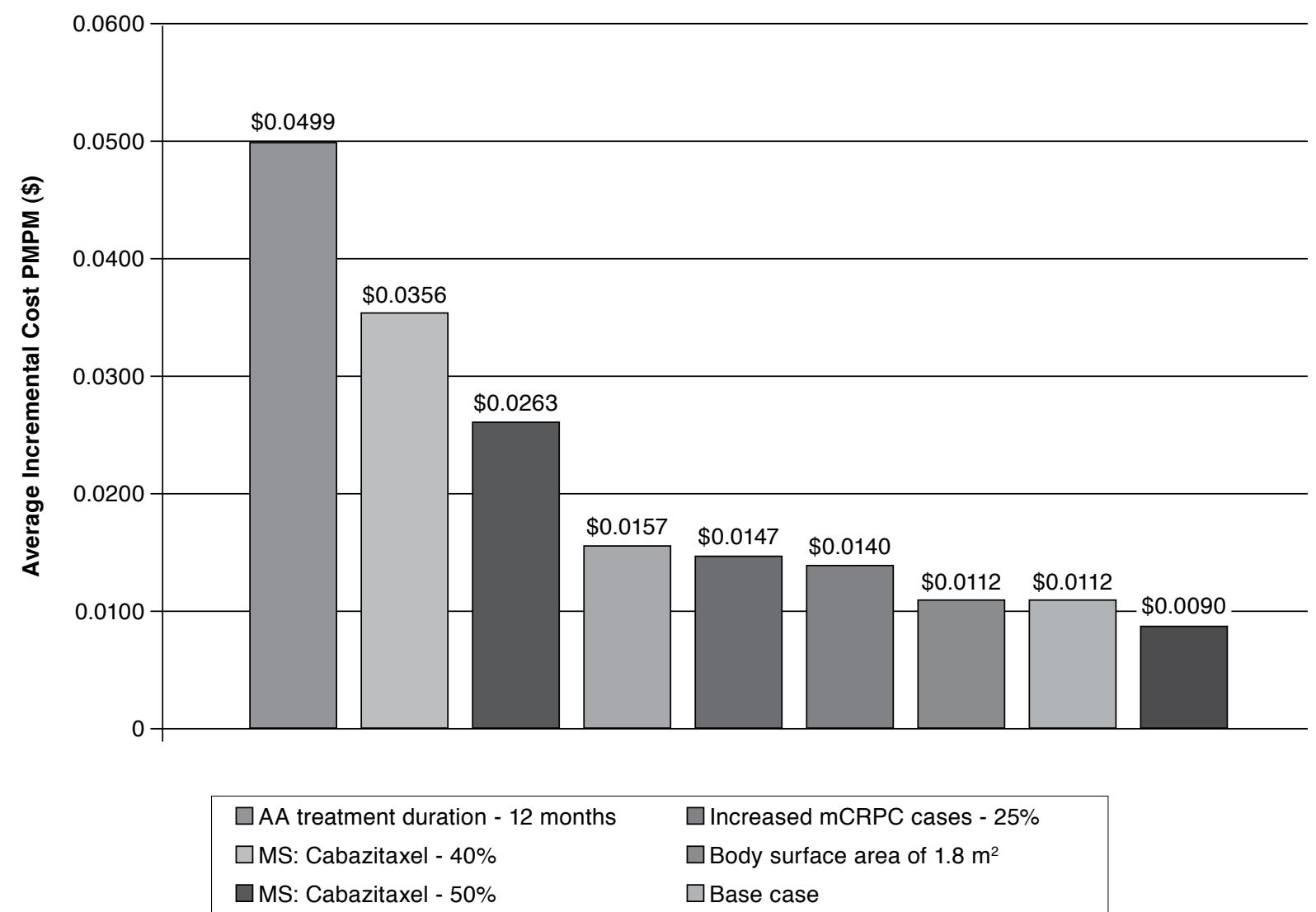

\author{
$\square$ Increased mCRPC cases - $25 \%$ \\ $\square$ Body surface area of $1.8 \mathrm{~m}^{2}$ \\ $\square$ Base case
}

$\square$ Decreased mCRPC cases - 25\%

\section{Limitations}

Given the limited nature of literature related to symptomatic mCRPC, data to inform the BIM presented here were limited, making the model subject to limitations. The calculated epidemiology estimates were derived from prostate cancer incidence reported in U.S. epidemiology statistics and disease progression data from published trials. If the population of mCRPC patients within the health plan population differs significantly from the derived patient population assumptions, the results of the BIM may not be accurate for that plan.

The model does not include management costs such as physician visits and disease monitoring, which may vary by treatment given. While the abiraterone acetate prescribing information suggested liver function test monitoring, it is commonly recommended that patients on chemotherapy have regular complete blood count measures. ${ }^{10}$ Therefore, it may be reasonable to assume that the disease monitoring cost of abiraterone acetate patients will have minimal or no budgetary impact as compared to monitoring for other chemotherapies. The main driver of results in the model were drug costs and market share.

The toxicity costs required significant inputs from experts to determine the percentage treated at inpatient and outpatient settings as well as outpatient procedures and medications. While expert opinion is not ideal, it is widely used in models when published data cannot be identified.

The initial model did not consider sipuleucel-T. However, sipuleucel-T is indicated for treatment of asymptomatic or minimally symptomatic mCRPC and not specifically for the more severe patients in the post-docetaxel disease spectrum. The model was developed prior to commercial availability of 


\section{Budgetary Impact on a U.S. Health Plan Adopting Abiraterone Acetate Plus Prednisone for the Treatment of Patients with Metastatic Castration-Resistant Prostate Cancer}

enzalutamide, a new androgen receptor inhibitor approved by the U.S. Food and Drug Administration in 2012. The median duration of treatment observed in the pivotal enzalutamide clinical trial was 8.3 months as compared with 8 months for abiraterone acetate; ${ }^{12,40}$ however, the listed AWP of a 30-day supply of enzalutamide is $\$ 7,778$ (AWP less $13 \%$ ) ) $^{25,41}$ which is significantly higher than the AWP less $13 \%$ of a 30 -day supply of abiraterone in the current model, which is less than $\$ 6,000$ (AWP less 13\%). In a scenario where abiraterone acetate, a less costly treatment, takes market share from a more costly treatment such as enzalutamide, an overall more favorable PMPM would be realized assuming similar duration of therapy.

It should be noted that this BIM does not consider the clinical benefits of agents, as is usual for this type of model. Abiraterone, cabazitaxel, and enzalutamide have all demonstrated survival benefit. Cabazitaxel showed a 2.4-month survival benefit (hazard ratio [HR] for death: $0.70 ; P<0.0001$ ) over mitoxantrone + prednisone in MCRPC patients who had received prior docetaxel therapy. ${ }^{9}$ A 3.9 - to 4.6 -month survival benefit (HR for death: 0.65 to $0.74 ; P<0.0001$ ) was observed for abiraterone + prednisone as compared with placebo + prednisone in MCRPC patients treated after failure on docetaxel at the 2 pre-planned analysis points. ${ }^{11,13}$ Enzalutamide showed a 4.8-month increase in survival benefit compared with placebo (HR 0.63; 95\% confidence interval, 0.53 to $0.75 ; P<0.001$ )..$^{40}$

The BIM base case results represent the best approximation of the budgetary impact of abiraterone given the inputs available and assumptions explicitly listed. In addition, it is important to note that in light of the limitations of the present analysis, a further advantage of BIMs such as this is customizability. Inputs can be modified based on specific settings and as additional data become available. There are further strengths of the current analysis, notably the inclusion of a commercialonly and commercial/Medicare combined perspective. A 1998 study of economic impact of prostate cancer found that $47.3 \%$ of costs were paid by Medicare alone, making consideration of a Medicare population perspective critical. ${ }^{42}$

\section{Conclusions}

The model results indicate that reimbursement for abiraterone for treatment of mCRPC patients who have received prior chemotherapy containing docetaxel may have a neutral impact on the budget of a U.S. health plan, given the relatively small size of the eligible population and its manageable safety profile. The sensitivity analyses addressing the components of uncertainty in the model show that the budgetary impact of abiraterone for these patients is likely low.

\section{Authors}

SONJA SORENSEN, MPH, is Senior Research Scientist, Health Economics and Epidemiology, Evidera, Bethesda, Maryland. LORIE ELLIS, PhD, is Associate Director, Health Economics and Outcomes Research; YING WU, PhD, MPH, is Associate Director; and MEKRÉ SENBETTA, PharmD, is Senior Director, Oncology/ Nephrology Outcomes Research, Janssen Scientific Affairs, Horsham, Pennsylvania. VALERIE HUTCHINS, BA, and JOHN E. LINNEHAN, MPH, are Research Associates, United BioSource Corporation, Bethesda, Maryland.

AUTHOR CORRESPONDENCE: Mekré Senbetta, PharmD, Senior Director, Oncology/Nephrology Outcomes Research, Janssen Scientific Affairs, Horsham, PA 19044.

Tel.: 215.325.2403; Fax: 215.325.4178;

E-mail:MSenbet1@its.jnj.com.

\section{DISCLOSURES}

This study was funded by Janssen Scientific Affairs, a unit of Johnson \& Johnson, which also employs Ellis, Wu, and Senbetta, who as employees are also stockholders in Johnson \& Johnson. Janssen Scientific Affairs employed United BioSource Corporation as a collaborator on this study.

Senbetta, Ellis, Sorenson, Hutchins, Linnehan, and Wu participated in the design of this study and in data interpretation, manuscript writing, and manuscript revision. Sorensen, Hutchins, and Linnehan were responsible for data collection.

\section{REFERENCES}

1. American Cancer Society. Cancer Facts \& Figures 2010. Atlanta, GA American Cancer Society; 2010. Available at: http://www.cancer.org/acs/ groups/content/@epidemiologysurveilance/documents/document/acspc026238.pdf. Accessed July 8, 2013.

2. National Cancer Institute. Cancer trends progress report 2009/2010 update. 2010. Available at: http://www.cancer.gov/newscenter/newsfromnci/2010/ProgressReport2010. Accessed August 19, 2013.

3. Solo K, Mehra R, Dhawan R, et al. Prevalence of prostate cancer (PC) clinical states (CS) in the United States: Estimates using a dynamic progression model. J Clin Oncol. 2011;29(Suppl):abs-4637.

4. Scher HI, Morris MJ, Kelly WK, Schwartz LH, Heller G. Prostate cancer clinical trial end points: "RECIST"ing a step backwards. Clin Cancer Res. 2005;11(14):5223-32.

5. Crawford ED, Eisenberger MA, McLeod DG, et al. A controlled trial of leuprolide with and without flutamide in prostatic carcinoma. N Engl J Med. 1989;321(7):419-24.

6. Eisenberger MA, Blumenstein BA, Crawford ED, et al. Bilateral orchiectomy with or without flutamide for metastatic prostate cancer. N Engl J Med. 1998;339(15):1036-42.

7. Schmitt B, Wilt TJ, Schellhammer PF, et al. Combined androgen blockade with nonsteroidal antiandrogens for advanced prostate cancer: a systematic review. Urology. 2001;57(4):727-32.

8. Tannock IF, de Wit R, Berry WR, et al. Docetaxel plus prednisone or mitoxantrone plus prednisone for advanced prostate cancer. N Engl J Med. 2004;351(15):1502-12.

9. de Bono JS, Oudard S, Ozguroglu M, et al. Prednisone plus cabazitaxel or mitoxantrone for metastatic castration-resistant prostate cancer progressing after docetaxel treatment: a randomised open-label trial. Lancet. 2010;376(9747):1147-54. 


\section{Budgetary Impact on a U.S. Health Plan Adopting Abiraterone Acetate Plus Prednisone for the Treatment of Patients with Metastatic Castration-Resistant Prostate Cancer}

10. Jevtana (cabazitaxel) injection, $60 \mathrm{mg} / 1.5 \mathrm{~mL}$, intravenous infusion (IV) [package insert]. Sanofi-aventis. Revised May 2013. Available at: http://products.sanofi.us/jevtana/jevtana.html. Accessed August 19, 2013.

11. de Bono JS, Logothetis CJ, Molina A, et al. Abiraterone and increased survival in metastatic prostate cancer. N Engl J Med. 2011;364:1995-2005.

12. Zytiga (abiraterone acetate) tablets. Janssen Biotech. December 2012. Available at: http://www.zytiga.com/sites/default/files/pdf/full_product_ information.pdf. Accessed September 23, 2013.

13. Fizazi K, Scher HI, Molina A, et al. Abiraterone acetate for treatment of metastatic castration-resistant prostate cancer: final overall survival analysis of the COU-AA-301 randomised, double-blind, placebo-controlled phase 3 study. Lancet Oncol. 2012;13(10):983-92.

14. Mauskopf JA, Sullivan SD, Annemans L, et al. Principles of good practice for budget impact analysis: report of the ISPOR Task Force on good research practices--budget impact analysis. Value Health. 2007;10(5):336-47.

15. FMCP Format Executive Committee. The AMCP format for formulary submissions, version 3.0. A format for submission of clinical and economic evidence of pharmaceuticals in support of formulary consideration. Foundation for Managed Care Pharmacy and Academy of Managed Care Pharmacy. October 2009. Available at: http://www.amcp.org/WorkArea/ DownloadAsset.aspx?id=9127. Accessed July 8, 2013.

16. Johnson \& Johnson. Ingenix Employer database from 2002 to 2008 Data on file. 2011.

17. U.S. Census Bureau. Annual estimates of the residential population by sex and five-year age groups for the United States, July 1, 2009. Available at: http://www.census.gov/popest/data/historical/2000s/vintage_2009/index. html. Accessed August 5, 2010.

18. U.S. Census Bureau. U.S. Interim projections by age, sex, race, and Hispanic origin: 2000-2050. Available at: http://www.census.gov/population/projections/data/national/usinterimproj.html. Accessed July 13, 2013.

19. Choueiri TK, Xie W, D'Amico AV, et al. Time to prostate-specific antigen nadir independently predicts overall survival in patients who have metastatic hormone-sensitive prostate cancer treated with androgen-deprivation therapy. Cancer. 2009;115(5):981-87.

20. Madan RA, Gulley JL, Schlom J, et al. Analysis of overall survival in patients with nonmetastatic castration-resistant prostate cancer treated with vaccine, nilutamide, and combination therapy. Clin Cancer Res. 2008;14(14):4526-31.

21. Nelson JB, Love W, Chin JL, et al. Phase 3, randomized, controlled trial of atrasentan in patients with nonmetastatic, hormone-refractory prostate cancer. Cancer. 2008;113(9):2478-87.

22. Ross RW, Xie W, Regan MM, et al. Efficacy of androgen deprivation therapy (ADT) in patients with advanced prostate cancer: association between Gleason score, prostate-specific antigen level, and prior ADT exposure with duration of ADT effect. Cancer. 2008;112(6):1247-53.

23. Mehra M, Wu Y, Dhawan R. Healthcare resource use in advanced prostate cancer patients treated with docetaxel. J Med Econ. 2012;15(5):836-43.

24. Janssen Biotech Inc. Data on file. Janssen Biotech, Inc.

25. Academy of Managed Care Pharmacy. AMCP guide to pharmaceutical payment methods, 2009 update (version 2.0). J Manag Care Pharm. 2009;15(6 Suppl A):S1-S61. Available at: http://www.amcp.org/data/ jmcp/1002.pdf

26. Novantrone (mitoXANTRONE) injection concentrate, intravenous infusion (IV) [package insert]. EMD Serono. May 2010. Available at: http://www accessdata.fda.gov/drugsatfda_docs/label/2010/019297s033s034lbl.pdf. Accessed August 19, 2013.
27. Taxotere (docetaxel) injection concentrate, intravenous infusion (IV) [package insert]. Sanofi-aventis. Revised May 2010. Available at: http://www. accessdata.fda.gov/drugsatfda_docs/label/2010/020449s059lbl.pdf. Accessed July 8, 2013

28. Stokes ME, Muehlenbein CE, Marciniak MD, et al. Neutropenia-related costs in patients treated with first-line chemotherapy for advanced nonsmall cell lung cancer. J Manag Care Pharm. 2009;15(8):669-82. Available at: http://www.amcp.org/WorkArea/DownloadAsset.aspx?id=8233.

29. Agency for Healthcare Research and Quality. Healthcare cost and utilization project (HCUP). Nationwide inpatient sample (NIS). 2009. Available at: http://www.ahrq.gov/data/hcup/. Accessed July 8, 2013.

30. U.S. Department of Labor. Bureau of Labor Statistics. Archived Consumer Price Index detailed report information. 2007 Consumer Price Index detailed report. Available at: http://www.bls.gov/cpi/cpi_dr.htm\#2000. Accessed July 8, 2013.

31. Pashos CL, Larholt K, Fraser KA, McKenzie RS, Senbetta M, Piech CT. Outcomes of erythropoiesis-stimulating agents in cancer patients with chemotherapy-induced anemia. Support Care Cancer. 2012;20(1):159-65.

32. National Comprehensive Cancer Network. NCCN Clinical practice guidelines in oncology: cancer- and chemotherapy-induced anemia. 2011. Available at: http://www.nccn.org/professionals/physician_gls/f_guidelines asp" \l "anemia. Accessed July 8, 2013.

33. National Comprehensive Cancer Network. NCCN Clinical practice guidelines in oncology: cancer-related fatigue. 2011. Available at: http:// www.nccn.org/professionals/physician_gls/f_guidelines.asp" \l "fatigue. Accessed July 8, 2013.

34. Centers for Medicare and Medicaid Services. Physician fee schedule. National payment amount file CY 2012. February 29, 2012. Available at: http://www.cms.gov/Medicare/Medicare-Fee-for-Service-Payment/ PhysicianFeeSched/PFS-National-Payment-Amount-File.html. Accessed July 8, 2013.

35. RED BOOK Online. 2011 ed. Montvale, NJ: Thomson Healthcare; 2011: Available at: http://www.micromedexsolutions.com/home/dispatch. Accessed August 19, 2013.

36. MAG Mutual Healthcare Solutions Inc. Physicians' Fee \& Coding Guide, 2012. Vol 1. Duluth, GA: Mag Mutual Healthcare Solutions Inc.; 2012

37. Centers for Medicaid and Medicare Services. Medicare Part B drug average sales price. January 2012 ASP pricing file and not otherwise classified pricing file. 2011. Available at: http://www.cms.gov/Medicare/Medicare-Feefor-Service-Part-B-Drugs/McrPartBDrugAvgSalesPrice/2012ASPFiles.html. Accessed September 23, 2013.

38. Ho J, Zhang L, Todorova L, Whillans F, Corey-Lisle P, Yuan Y. Budget impact analysis of ixabepilone used according to FDA approved labeling in treatment-resistant metastatic breast cancer. J Manag Care Pharm. 2009;15(6):467-75. Available at: http://www.amcp.org/WorkArea/ DownloadAsset.aspx?id=8179.

39. Ramsey SD, Clarke L, Kamath TV, Lubeck D. Evaluation of erlotinib in advanced non-small cell lung cancer: impact on the budget of a U.S. health insurance plan. J Manag Care Pharm. 2006;12(6):472-78. Available at: http:// www.amcp.org/WorkArea/DownloadAsset. aspx?id=7414.

40. Xtandi (enzalutamide capsules). Medivation, Inc. and Astellas Pharma US. 2012. Available at: http://www.fda.gov/Drugs/InformationOnDrugs/ ApprovedDrugs/ucm317997.htm. Accessed July 8, 2013.

41. RED BOOK Online. 2012 ed. Montvale, NJ: Thomson Healthcare; 2012: Available at: http://www.micromedexsolutions.com/home/dispatch. Accessed August 19, 2013.

42. Max W, Rice DP, Sung HY, Michel M, Breuer W, Zhang X. The economic burden of prostate cancer, California, 1998. Cancer. 2002;94(11):2906-13. 